\title{
Clinical spectrum of early onset cerebellar ataxia with retained tendon reflexes: an autosomal recessive ataxia not to be missed
}

\author{
Espectro clínico da ataxia cerebelar de início precoce com reflexos mantidos: uma ataxia \\ autossômica recessiva para não ser esquecida
}

José Luiz Pedroso, Pedro Braga-Neto, Irapuá Ferreira Ricarte, Marcus Vinicius Cristino Albuquerque, Orlando Graziani Povoas Barsottini

\begin{abstract}
Autosomal recessive cerebellar ataxias are a heterogeneous group of neurological disorders. In 1981, a neurological entity comprised by early onset progressive cerebellar ataxia, dysarthria, pyramidal weakness of the limbs and retained or increased upper limb reflexes and knee jerks was described. This disorder is known as early onset cerebellar ataxia with retained tendon reflexes. In this article, we aimed to call attention for the diagnosis of early onset cerebellar ataxia with retained tendon reflexes as the second most common cause of autosomal recessive cerebellar ataxias, after Friedreich ataxia, and also to perform a clinical spectrum study of this syndrome. In this data, 12 patients from different families met all clinical features for early onset cerebellar ataxia with retained tendon reflexes. Dysarthria and cerebellar atrophy were the most common features in our sample. It is uncertain, however, whether early onset cerebellar ataxia with retained tendon reflexes is a homogeneous disease or a group of phenotypically similar syndromes represented by different genetic entities. Further molecular studies are required to provide definitive answers to the questions that remain regarding early onset cerebellar ataxia with retained tendon reflexes.
\end{abstract}

Key words: ataxias, autosomal recessive cerebellar ataxias, early onset cerebellar ataxia with retained tendon reflexes, EOCA.

\section{RESUMO}

As ataxias cerebelares autossômicas recessivas são um grupo heterogêneo de doenças neurológicas. Em 1981, foi descrita uma entidade neurológica incluindo ataxia cerebelar progressiva de início precoce, disartria, liberação piramidal e manutenção ou aumento dos reflexos tendíneos nos membros superiores e inferiores. Essa síndrome é conhecida como ataxia cerebelar de início precoce com reflexos mantidos. Neste artigo, o objetivo foi chamar a atenção para o diagnóstico de ataxia cerebelar de início precoce com reflexos mantidos como a segunda causa mais comum de ataxia cerebelar autossômica recessiva, após a ataxia de Friedreich, e também realizar um estudo do espectro clínico da síndrome. Doze pacientes de diferentes famílias preencheram os critérios clínicos para ataxia cerebelar de início precoce com reflexos mantidos. Disartria e atrofia cerebelar foram as características mais frequentes. No entanto, não há consenso se a ataxia cerebelar de início precoce com reflexos mantidos é uma doença homogênea ou um grupo de síndromes com fenótipos semelhantes representadas por diferentes entidades genéticas. Estudos moleculares futuros são necessários para fornecer respostas definitivas para as questões pendentes em relação à ataxia cerebelar de início precoce com reflexos mantidos.

Palavras-Chave: ataxias, ataxia cerebelar autossômica recessiva, ataxia cerebelar de início precoce com reflexos mantidos, EOCA.

Autosomal recessive cerebellar ataxias (ARCA) are a heterogeneous group of neurological disorders characterized by degeneration or abnormal development of cerebellum and spinal cord, autosomal recessive inheritance and early onset beginning before the age of 20 years. This group encompasses a large number of unusual diseases and may be considered a diagnostic challenge ${ }^{1}$. The most frequent ARCA is Friedreich ataxia (FA), but other diseases include ataxia with vitamin $\mathrm{E}$ deficiency, ataxia telangiectasia, ataxia with ocular apraxia type 1 and type 2, autosomal recessive spastic ataxia of Charlevoix Saguenay (ARSACS), cerebrotendineous xanthomatosis, abetalipoproteinemia, Refsum disease and Marinesco-Sjögren syndrome. In most cases, diagnosis may be performed based on clinical and genetic evaluation ${ }^{1}$.

In 1981, Anita Harding described the clinical and genetic features of 20 families in which affected individuals had a

Department of Neurology, Ataxia Unit, Universidade Federal de São Paulo (UNIFESP), São Paulo SP, Brazil.

Correspondence: José Luiz Pedroso; Department of Neurology, Ataxia Unit, Universidade Federal de São Paulo; Rua Botucatu 740; 04023-900 São Paulo SP - Brasil; E-mail:jlpedroso.neuro@gmail.com

Conflict of interest: There is no conflict of interest to declare.

Received 26 October 2012; Received in final form 14 November 2012; Accepted 21 November 2012. 
progressive cerebellar ataxia developing within the first two decades, associated with dysarthria, pyramidal weakness of the limbs and retained or increased upper limb reflexes and knee jerks. This disorder is known as early onset cerebellar ataxia with retained tendon reflexes (EOCA) or Harding ataxia, and other case series were reported later ${ }^{2}$. EOCA is clinically distinct from FA, with significant differences between those neurological conditions ${ }^{2}$. Several reviews have pointed out that, although FA is the most common recessive ataxia worldwide, the diagnosis of this condition may be viewed with caution when brisk tendon reflexes are present. This is because FA presents with loss of tendon reflexes in 62 to $86 \%$ of patients ${ }^{3,4}$.

Frequently, EOCA has been excluded from ARCA list, since clinical features and genetic definition are not very well understood. In this article, we aimed to call attention for the diagnosis of EOCA as the second most common cause of ARCA, and also to perform a clinical spectrum study of this syndrome.

\section{METHODS}

A retrospective review from 486 medical records of patients attending at the Ataxia Unit, in the Universidade Federal de São Paulo, from February 2008 to September 2012, was performed. During this period, patients with different subtypes of cerebellar ataxias were followed-up in order to determine clinical and genetic diagnosis. Patients were divided into five categories based on age at onset, familial history, progression and laboratorial and genetic tests: autosomal dominant spinocerebellar ataxia (SCA), ARCA, sporadic ataxias, congenital ataxias and mithocondrial ataxias.
Patients with early onset symptoms were investigated for ARCA. Twelve patients from different families met all clinical features for EOCA. All patients had an early onset of ataxia symptoms (before 25 years old) with normal or brisk reflexes, and underwent biochemical analysis including albumin, alphafetoprotein and vitamin $\mathrm{E}$, genetic test for $\mathrm{FA}$, and brain imaging, in order to rule out other ARCA.

Information on age, age at onset, disease duration, consanguinity, ataxia severity (International Cooperative Ataxia Rating Scale (ICARS) and Scale for the Assessment and Rating of Ataxia (SARA)), reflexes, Babinski sign, spasticity, neuropathy (electroneuromyography), nystagmus, dysarthria and cerebellar atrophy were evaluated from medical records from all patients with suspected EOCA. All clinical details, including neurological examination and ataxia scales, were evaluated by the same researcher (JLP).

\section{RESULTS}

Table shows clinical and demographic features of the 12 patients with EOCA. Among patients with suspected EOCA, there was a slight male predominance (58.33\%). The mean age was $32.67 \pm 9.41$, mean age at onset was $17.25 \pm 3.86$, and mean disease duration, $15.42 \pm 6.66$ years. Regarding clinical features, the mean score on ICARS was 31.09 \pm 17.50 and on SARA was $12.82 \pm 5.38$. Genetic test for FA was negative in all patients. No correlation was found between ataxia severity (SARA and ICARS) and disease duration. Dysarthria and cerebellar atrophy were the most common features and were present in 10 of 12 patients (Fig 1).

FA was diagnosed in 37 patients and was the most common ARCA in our Ataxia Unit. EOCA was the second

Table. Clinical features found in early onset ataxia with retained reflexes.

\begin{tabular}{|c|c|c|c|c|c|c|c|c|c|c|c|c|c|c|c|c|}
\hline & $\begin{array}{l}\bar{d} \\
\frac{1}{0} \\
\overline{0} \\
0 \\
0\end{array}$ & $\underset{\mathbb{L}}{\stackrel{\infty}{<}}$ & 운 & 음 & 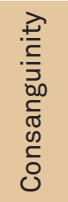 & 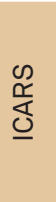 & 离 & $\stackrel{\frac{\pi}{S}}{5}$ & $\stackrel{\check{\alpha}}{\underline{x}}$ & $\frac{\alpha}{4}$ & $\mathscr{\varpi}$ & $\begin{array}{l}\frac{\lambda}{0} \\
\frac{1}{0} \\
0 \\
0 \\
0 \\
0 \\
0\end{array}$ & 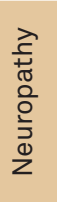 & 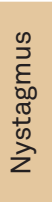 & 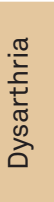 & 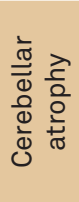 \\
\hline 1 & $M$ & 19 & 14 & 5 & Yes & 27 & 9 & +++ & +++ & +++ & $A$ & $A$ & $A$ & $P$ & $P$ & $P$ \\
\hline 2 & $M$ & 39 & 22 & 17 & No & 54 & 20 & ++++ & ++++ & +++ & $P$ & $P$ & $P$ & $P$ & $A$ & A \\
\hline 3 & $\mathrm{~F}$ & 22 & 16 & 6 & No & 23 & 12 & ++++ & +++ & ++ & $A$ & $A$ & $A$ & $A$ & $P$ & $P$ \\
\hline 4 & $M$ & 37 & 17 & 20 & No & 33 & 14 & ++ & ++ & +++ & $A$ & $A$ & - & $P$ & $P$ & $P$ \\
\hline 5 & $M$ & 52 & 25 & 27 & Yes & 15 & 10 & +++ & +++ & +++ & $A$ & $A$ & - & $A$ & $P$ & P \\
\hline 6 & $M$ & 28 & 13 & 15 & Yes & 17 & 11 & ++ & ++ & +++ & $A$ & $A$ & - & $P$ & $\mathrm{P}$ & P \\
\hline 7 & $\mathrm{~F}$ & 36 & 21 & 15 & No & 54 & 18 & ++++ & ++++ & ++++ & $A$ & $A$ & - & $P$ & $P$ & $P$ \\
\hline 8 & $\mathrm{~F}$ & 21 & 12 & 9 & No & 38 & 15 & ++++ & ++++ & ++++ & $P$ & $A$ & $P$ & $P$ & $P$ & A \\
\hline 9 & $F$ & 36 & 17 & 19 & Yes & 19 & 7 & ++ & ++ & ++ & $A$ & $A$ & $A$ & $A$ & $P$ & P \\
\hline 10 & $M$ & 40 & 16 & 24 & Yes & 58 & 22 & +++ & +++ & +++ & $A$ & $A$ & $A$ & $P$ & $P$ & P \\
\hline 11 & $F$ & 32 & 19 & 13 & Yes & 14 & 9 & +++ & +++ & +++ & A & $A$ & $A$ & $A$ & $P$ & $P$ \\
\hline 12 & $M$ & 30 & 15 & 15 & No & 13 & 6 & +++ & +++ & +++ & $A$ & $A$ & $A$ & $A$ & $A$ & $P$ \\
\hline
\end{tabular}

M: Male; F: Female; AO:Age at onset; DD: Disease duration; ICARS: International Cooperative Ataxia Rating Scale; SARA: Scale for the Assessment and Rating of Ataxia; ULR: Upper limbs reflexes; KR: Knee reflexes; AR: Achilles reflexes; BS: Babinski sign; P: Present; A: Absent. 

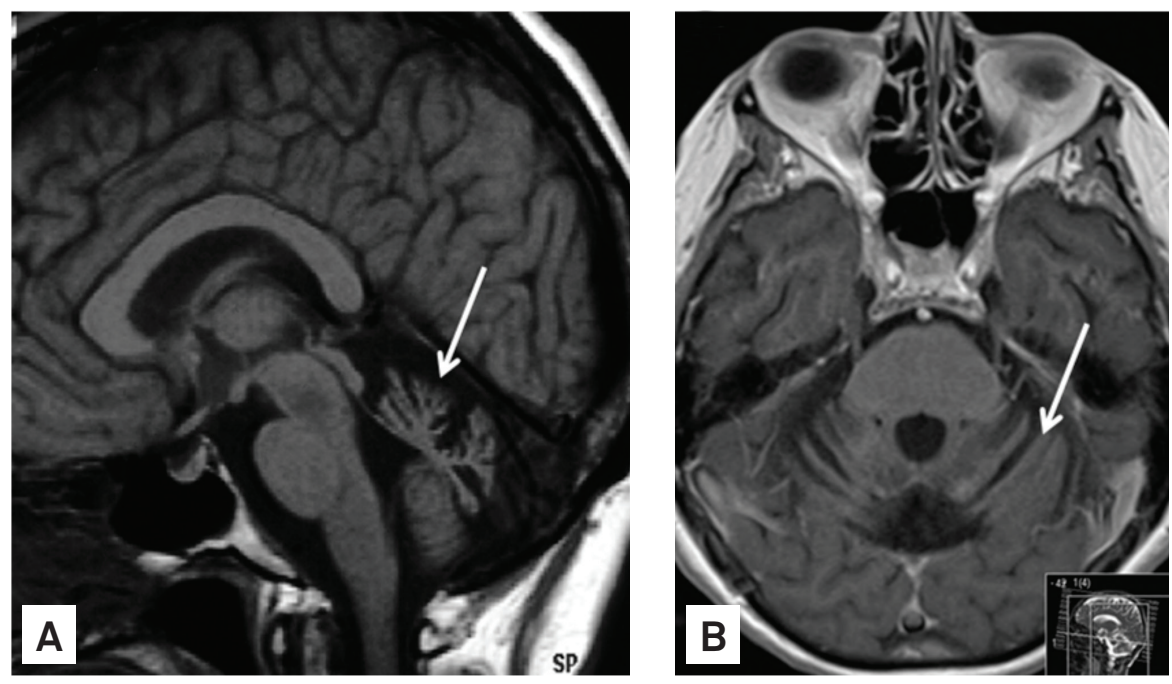

Fig 1. (A) Sagittal T1-weighted and (B) axial T1-weighted brain MRI disclosing marked global cerebellar atrophy in a patient with early onset ataxia with retained reflexes.

most common cause of ARCA (12 patients), followed by ataxia with oculomotor apraxia type 2 (7 patients), ataxia telangiectasia (4 patients), ARSACS (4 patients), ataxia with vitamin E deficiency (3 patients) and cerebrotendineous xanthomatosis (1 patient). There are several patients under investigation for ataxia with oculomotor apraxia type 1 (3 patients), coenzyme Q10 deficiency (2 patients), mithocondrial ataxia (3 patients) and Marinesco-Sjögren syndrome (1 patient). No patients with Refsun disease and abetalipoproteinemia were confirmed. Congenital ataxias were not included in this list.

\section{DISCUSSION}

Our study highlights how relevant is to consider EOCA in the differential diagnosis of ARCA, since it might correspond to its second most common cause. An autosomal recessive inherited disorder is suggested, as half of the patients had consanguineous parents. Additionally, dysarthria was presented in almost all patients and might be considered a frequent neurological finding. We also observed that almost all patients presented with cerebellar atrophy on brain magnetic resonance imaging (MRI) studies, in opposite to FA patients. Conversely, spasticity was an unusual clinical feature. No correlation was found between ataxia severity and disease duration, which express that EOCA has a heterogeneous progression.

Although the phenotype of FA has classical findings, such as loss of tendon reflexes, sensory loss, scoliosis, foot deformity, diabetes mellitus and cardiac abnormalities, there are variations in the clinical presentation. These include the late onset Friedreich ataxia (LOFA) and also Friedreich ataxia with retained reflexes (FARR) $)^{5,6}$. Thus, the presence of retained reflexes does not exclude the diagnosis of FA, and a genetic test is recommended despite an atypical ARCA presentation? ${ }^{7}$. No patient with FARR phenotype was identified in our study. A normal brain magnetic resonance imaging (MRI) without cerebellar atrophy is also a remarkable finding in FA patients $(\text { Fig } 2)^{8,9}$.

One of the largest series of EOCA described by Chio et al. evaluated patients for 50 years. They concluded that EOCA was the third most common cause of ARCA, after FA and ataxia telangiectasia ${ }^{10}$. Klockgether et al. evaluated 14 patients with EOCA and compared clinical, electrophysiological and MRI observations with FA patients. Sensory disturbances, foot deformity and scoliosis were encountered less frequently in EOCA than in FA patients. Electrophysiological findings in EOCA were variable and pointed out to an axonal degeneration in peripheral nerves. Our study demonstrated that axonal neuropathy was present in only $25 \%$ of patients. Cerebellar atrophy was a frequent neuroimaging feature in all EOCA series, in opposite to $\mathrm{FA}^{9}$. The demonstration of cerebellar atrophy in the majority of EOCA patients supported the view that EOCA was distinct from $\mathrm{FA}^{9}$. Additionally, some data also has demonstrated that EOCA is characterized by a heterogeneous progression ${ }^{11,12}$.

Although past decade has seen great advances in unraveling the biological basis of hereditary ataxias, knowledge on the genetic features of EOCA is still extremely restricted. Sporadic reports have demonstrated new mutations in recessive ataxias. For instance, SYNE1 mutation is a gene responsible for a recessive inherited pure cerebellar ataxia ${ }^{13}$. Concerning that genetic test is not available for the diagnosis of EOCA, we strongly recommend a biomarker investigation, including albumin, alphafetoprotein and vitamin $\mathrm{E}$, and genetic test for FA, in order to exclude other potential ARCA ${ }^{14}$. 

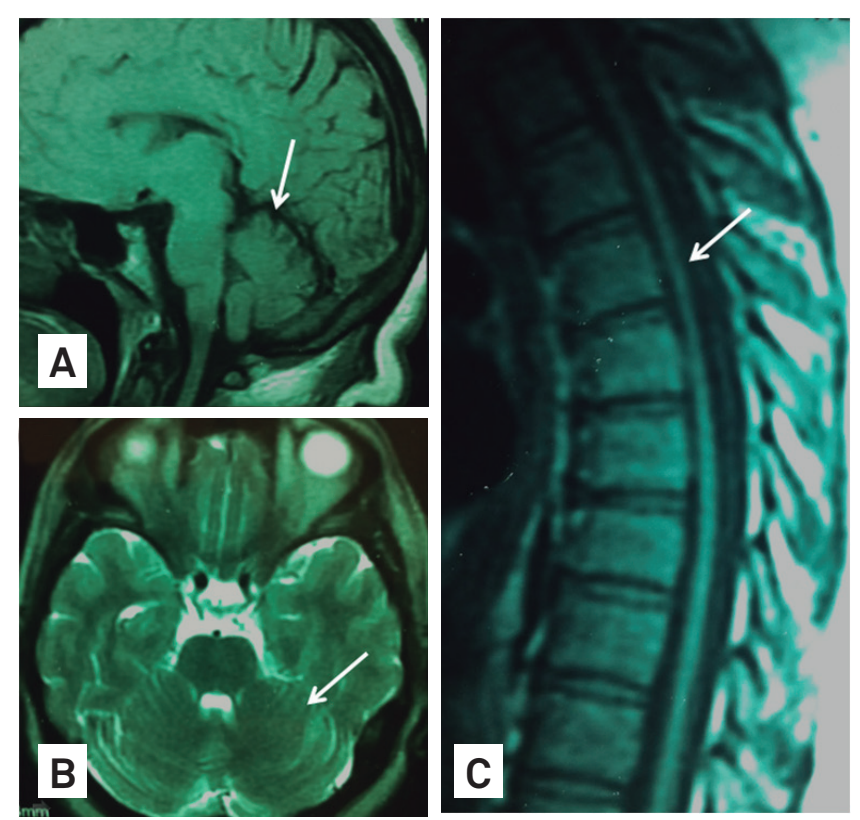

Fig 2. (A) Sagittal T1-weighted and axial T2-weighted brain MRI disclosing normal cerebellar volume, without atrophy, in a patient with Friedreich ataxia; (C) sagittal T1-weighted thoracic spine MRI of the same patient, showing atrophy of the spinal cord.
Interestingly, although patients described in our sample mostly had brisk reflexes, spasticity was present only in one patient, similarly to other series ${ }^{15}$. This is a crucial issue, since spasticity in a context of ARCA (also called hereditary spasticataxias) might suggest other rare neurological conditions, such as ARSACS, hereditary spastic paraplegia and autosomal recessive spastic ataxia ${ }^{16,17}$. Therefore, spasticity should be considered a neurological hallmark against the diagnosis of EOCA.

On the whole, this article highlighted the importance to consider EOCA as the second most common ARCA. The lack of a genetic marker should not be a limitation to consider this syndrome. Also, we reinforce the relevance to exclude other ARCA, by performing a biochemical investigation and genetic test for FA in order to exclude FARR. Based on this data, the clinical spectrum of EOCA might include autosomal recessive inherited cerebellar ataxia, dysarthria, retained reflexes associated or not with neuropathy and cerebellar atrophy on brain MRI. It is uncertain, however, whether EOCA is a homogeneous disease or a group of phenotypically similar syndromes represented by different genetic entities. Further molecular studies are required to provide definitive answers to the questions that remain regarding EOCA.

\section{References}

1. Embiruçu EK, Martyn ML, Schlesinger D, Kok F. Autosomal recessive ataxias: 20 types, and counting. Arq Neuropsiquiatr 2009;67:1143-1156.

2. Harding AE. Early onset cerebellar ataxia with retained tendon reflexes: a clinical and genetic study of a disorder distinct from Friedreich's ataxia. J Neurol Neurosurg Psychiatry 1981;44:503-508.

3. Harding AE. Friedreich's ataxia: a clinical and genetic study of 90 families with an analysis of early diagnostic criteria and intrafamilial clustering of clinical features. Brain 1981;104:589-620.

4. Durr A, Cossee M, Agid Y, et al. Clinical and genetic abnormalities in patients with Friedreich's ataxia. N Engl J Med 1996;335:1169-1175.

5. Armani M, Zortea M, Pastorello E, et al. Friedreich's ataxia: clinical heterogeneity in two sisters. Neurol Sci 2006;27:140-142.

6. Palau F, Espinós C. Autosomal recessive cerebellar ataxias. Orphanet J Rare Dis 2006;1:47.

7. Schöls L, Amoiridis G, Przuntek H, Frank G, Epplen JT, Epplen C. Friedreich's ataxia. Revision of the phenotype according to molecular genetics. Brain 1997;120:2131-2140.

8. Fogel BL, Perlman S. Clinical features and molecular genetics of autosomal recessive cerebellar ataxias. Lancet Neurol 2007;6:245-257.

9. Klockgether T, Petersen D, Grodd W, Dichgans J. Early onset cerebellar ataxia with retained tendon reflexes. Clinical, electrophysiological and MRI observations in comparison with Friedreich's ataxia. Brain 1991;114:1559-1573.
10. Chio A, Orsi L, Mortara P, Schiffer D. Early onset cerebellar ataxia with retained tendon reflexes: prevalence and gene frequency in an Italian population. Clin Genet 1993;43:207-211.

11. De Castro M, Cruz-Martínez A, Vílchez JJ, et al. Early onset cerebellar ataxia and preservation of tendon reflexes: clinical phenotypes associated with GAA trinucleotide repeat expanded and nonexpanded genotypes.J Peripher Nerv Syst 1999;4:58-62.

12. Filla A, De Michele G, Cavalcanti F, et al. Clinical and genetic heterogeneity in early onset cerebellar ataxia with retained tendon reflexes. J Neurol Neurosurg Psychiatry 1990;53:667-670.

13. Gros-Louis F, Dupré N, Dion P, et al. Mutations in SYNE1 lead to a newly discovered form of autosomal recessive cerebellar ataxia. Nat Genet 2007;39:80-85.

14. Braga-Neto P, Dutra LA, Pedroso JL, Barsottini OG. Alpha-fetoprotein as a biomarker for recessive ataxias. Arq Neuropsiquiatr 2010;68:953-955.

15. Ozeren A, Arac N, Ulku A. Early-onset cerebellar ataxia with retained tendon reflexes. Acta Neurol Scand 1989;80:593-597.

16. de Bot ST, Willemsen MA, Vermeer S, Kremer HP, van de Warrenburg BP. Reviewing the genetic causes of spastic-ataxias. Neurology 2012;79:1507-1514.

17. Pedroso JL, Braga-Neto P, Abrahão A, et al. Autosomal recessive spastic ataxia of Charlevoix-Saguenay (ARSACS): typical clinical and neuroimaging features in a Brazilian family. Arq Neuropsiquiatr 2011;69:288-291. 